\title{
Verification of the functional effect of upright pelvis fixed support system dining chair with independence support function corresponding to eating and drinking trouble of the elderly
}

Junichi Fukaura $^{1,2,3}$, Tetsuji Tetsushi $^{3}, \underline{\text { Hideo Kaneko }}^{3}$ Takeshi Nanba $^{3}, \underline{\text { Yasuhiko Takeda }}^{3,4^{*}}$

${ }^{1}$ Chairman of the Japan Speech and Hearing sciences Association, Japan

${ }^{2}$ The Dysphagia Rehabilitation Society Councilor

${ }^{3}$ Department of Rehabilitation: (Speech and Hearing Sciences \& Physical Therapy), International University of Health and Welfare Graduate School, Okawa City, Fukuoka, Japan

${ }^{4}$ Body Tool Development Labo, Japan (Taigu Kaihatsu Laboratory): Ergonomics Researcher (verification test assistant)

Corresponding Author: Yasuhiko Takeda

Address: Body tool development labo Japan (Taigu Kaihatsu Laboratory): 2-109 Honmachi, Tottori City, Tottori pref. 680-0031 Japan. Ergonomics Researcher (Verification Test assistant), Tel: 0857-29-6281.

Received date: 04 July 2019; Accepted date: 15 July 2019; Published date: 22 July 2019

Citation: Fukaura J, Tetsushi T, Kaneko H, et al., "Verification of the functional effect of upright pelvis fixed support system dining chair with independence support function corresponding to eating and drinking trouble of the elderly". Asp Biomed Clin Case Rep, vol.2, no.2: 9-14, 2019.

Copyright () 2019 Fukaura J, Tetsushi T, Kaneko H, et al., This is an open-access article distributed under the Creative Commons Attribution License, which permits unrestricted use, distribution, and reproduction in any medium, provided the original work is properly cited.

\section{Abstract}

Information on smooth swallowing posture and swallowing function training is described in the medical literature. A dining chair was developed in Japan to protect the elderly from aspiration and aspiration pneumonia. We thought that if the function effect of the dining chair was actually exhibited, it would be vital information to all the elderly whose swallowing function continues to decline. We tried the verification test with electromyograph about the actual functional effect of the developed dining chair. Eating with the neck forward flexion (NFF) posture by the upright pelvis fixed support has shown a smooth swallowing effect which can be valuable information to elderly people around the world, whose swallowing function continues to decline.

\section{Keywords}

Dining Chair; Smooth Swallowing; Neck Forward Flexion; Aspiration; Elderly

\section{Introduction}

The rapid increase of aspiration and aspiration pneumonia in the elderly is a major social problem in Japan, and the elderly aged 70 and over who are hospitalized with aspiration pneumonia has reached 20,00o per day [1]. These aspirations take the life of healthy elderly people in an instant and continue to create elderly people in need of nursing care (wheelchair life, bedridden life) after long-term hospitalization with pneumonia. Dr. Siebens has defined the correct eating posture to prevent aspiration in six terms [2]. How to make and maintain the NFF posture in the dining chair is the biggest unsolved task for ergonomics researchers, rehabilitation researchers, physical therapy researchers and furniture manufacturing company developers.

A dining chair has been developed in Japan that has cleared all six items defined by Dr. Siebens. The developed chair is a new structure system dining chair that keeps theupright pelvic both ischial 
Citation: Fukaura J, Tetsushi T, Kaneko H, et al., "Verification of the functional effect of upright pelvis fixed support system dining chair with independence support function corresponding to eating and drinking trouble of the elderly". Asp Biomed Clin Case Rep, vol.2, no.2: 9-14, 2019.

\section{Case Report}

tuberosity are fixed on the chair seat surface, and both posterior superior iliac spine (PSIS) is fixed on the chair backrest to keep the NFF posture. In addition, it is a dining chair with high postural holding ability that has the independence support function of the elderly who works as a substitute for the eyes and hands of a caregiver who watches over and corrects their eating posture [3].

The world's first fixed pelvis dining chair was developed:

1. To protect elderly people from aspiration and choking accidents as a substitute for the eyes and hands of family members and carers who watch over meals. (Independence support function dining chair)

2. To contribute to extending the healthy life through a daily safe diet with smooth swallowing.

3. To stop the increase in the number of elderly requiring long-term care and to stop the decline in the quality of care associated with the shortage of care workers.
4. To reduce stress in family and caregivers.

In order to start comparison and verification, we obtained a new finding that the most efficient desk work posture (the NFF sitting posture) is a state where the 100 degrees chair back seat and the both PSIS contact exquisitely [4]. We conducted a comparative verification test between a general dining chair and a developed dining chair for smooth swallowing with an electromyograph that we considered to obtain the most objective evaluation [5].

\section{Subjects}

The verification test was aimed at the healthy elderly of 11 men and 10 women over the age of 65 who are living independent daily life without cerebrovascular disorder and dysphagia. The verification test was conducted with a document and a verbal explanation to all subjects, and a verification test after obtaining a written signature.

This study has obtained the approval of the international medical and Welfare University Ethics Review Committee (approval number: 15-IFH-3). neck forward flexion posture holding function dining chair

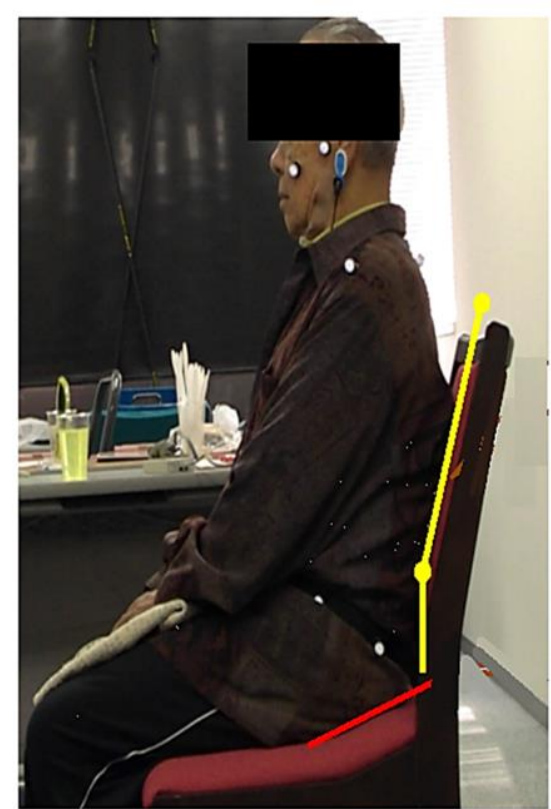

NFF posture holding function dining chair,

The backrest (height $45 \mathrm{~cm}$ ) is inclined backward 10 degrees until the bottom $20 \mathrm{~cm}$ and backward inclined 20 degrees in the upper part.

The seat surface (depth $40 \mathrm{~cm}$ ) ischial tuberosity peripheral portion is in a concave shape.

Fig-1 general dining chair:

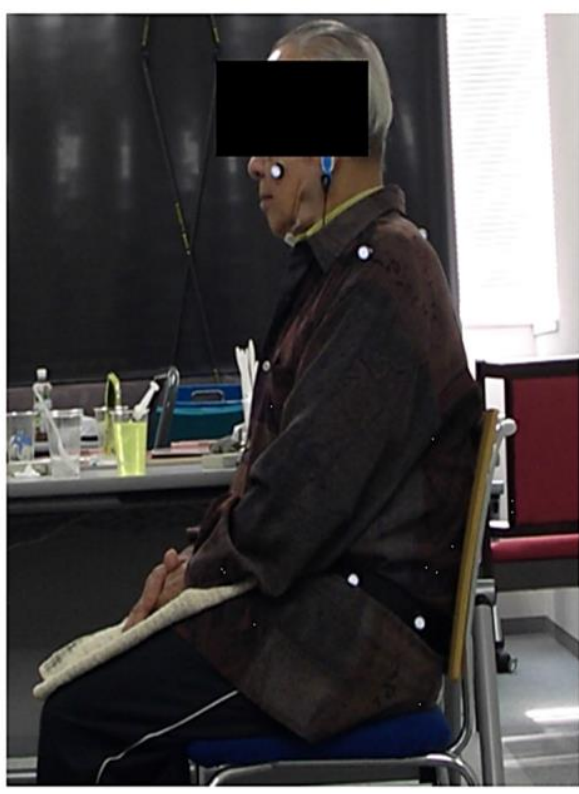

The general dining chair is $35 \mathrm{~cm}$ in depth and $35 \mathrm{~cm}$ in height. The inclination angle of the backrest was 10 degrees.

The angle of the seat surface was used that of 0 degrees. 
Citation: Fukaura J, Tetsushi T, Kaneko H, et al., "Verification of the functional effect of upright pelvis fixed support system dining chair with independence support function corresponding to eating and drinking trouble of the elderly". Asp Biomed Clin Case Rep, vol.2, no.2: 9-14, 2019.

\section{Method}

Using an upright pelvis fixed support dining chair (Fig-1) and a general dining chair (Fig-2), the electromyograms of the suprahyoid muscles were measured when swallowing jelly. The subject was seated in contact with the chair back and with the sole firmly in contact with the floor. Electromyographic measurements were conducted by two groups, those who operate the electromyograph and those who put jelly in their mouth. The measurement was performed after explaining that the $5 \mathrm{cc}$ jelly was swallowed without chewing. The measurements were conducted three times on two chairs each, and the measurement order was random. The anterior belly of the digastric muscle of the suprahyoid muscles surrounded by mental protuberance and mandible were recorded EMG as a swallowing muscle [6]. The recording electrode was attached to the anterior belly of the digastric muscle with a Metz blue sensor as an electrode width of 20 $\mathrm{mm}$. The non-function electrodes were affixed to the earlobe. The electromyograph was using the EMG Master Km-mercury (manufactured by Mediarea Support Company Union Co., Ltd.). The sampling frequency was low-pass filtered (cut-off frequency $5 \mathrm{~Hz}$ ) after full-wave rectification at $1 \mathrm{kHz}$. The point at which the waveform of mean baseline amplitude + 2SD or more lasted for $50 \mathrm{~ms}$ was defined as the

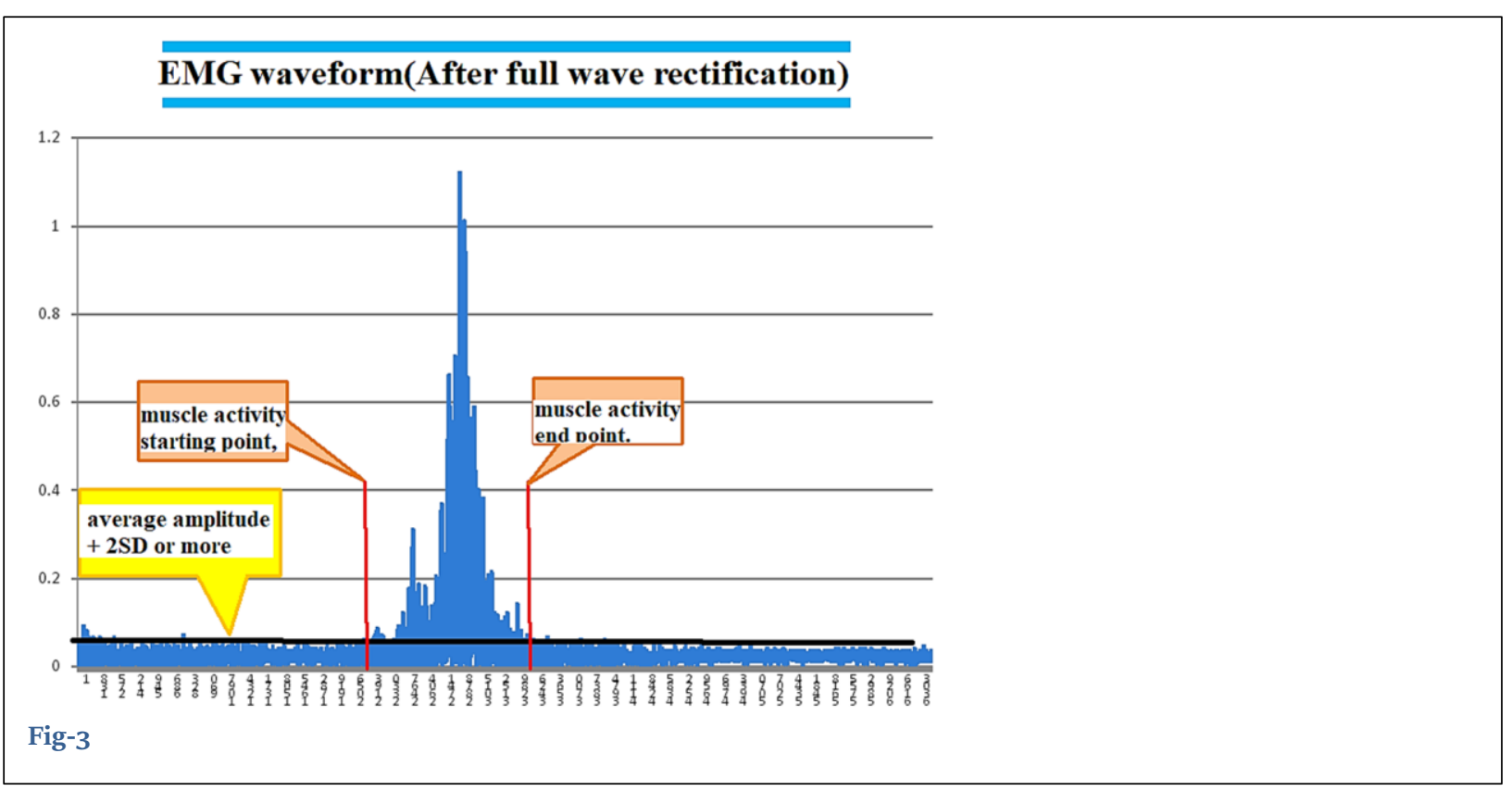

muscle activity start point and the point at which the mean amplitude of the baseline +2 SD or less was endpoint of muscle activity. The suprahyoid muscles activity duration during swallowing was calculated based on the start and endpoints of muscles activity (Fig-3).

The statistical test was performed with a correspondence T-Test. The statistical software used SPSS (Ver.19), and the risk rate was significant with less than $5 \%$.

\section{Results}

8 people were not able to analyze the waveform of the EMG, and finally analyzed the results of 13 subjects (average age $72.23 \pm 6.01$ years) of 10 male 3 women (Table-1).

Suprahyoid muscles activity duration showed a significant difference in NFF posture holding function dining chair1.13 \pm 0.59 seconds, general dining chair $1.43 \pm 0.77$ seconds $($ P-value $=0.045<0.05)($ Fig-4 $)$.

\section{Discussion}

In order to keep the pelvis upright, the activity of the iliopsoas muscle is essential, and the iliopsoas muscle has an action to bend the hip joint. If try to hold the upright pelvic sitting posture in a general chair sitting position, the hip joint will bend further and the sole will try to move away from the floor surface. In the case of 
Citation: Fukaura J, Tetsushi T, Kaneko H, et al., "Verification of the functional effect of upright pelvis fixed support system dining chair with independence support function corresponding to eating and drinking trouble of the elderly". Asp Biomed Clin Case Rep, vol.2, no.2: 9-14, 2019.

\section{suprahyoid muscles action potential duration}

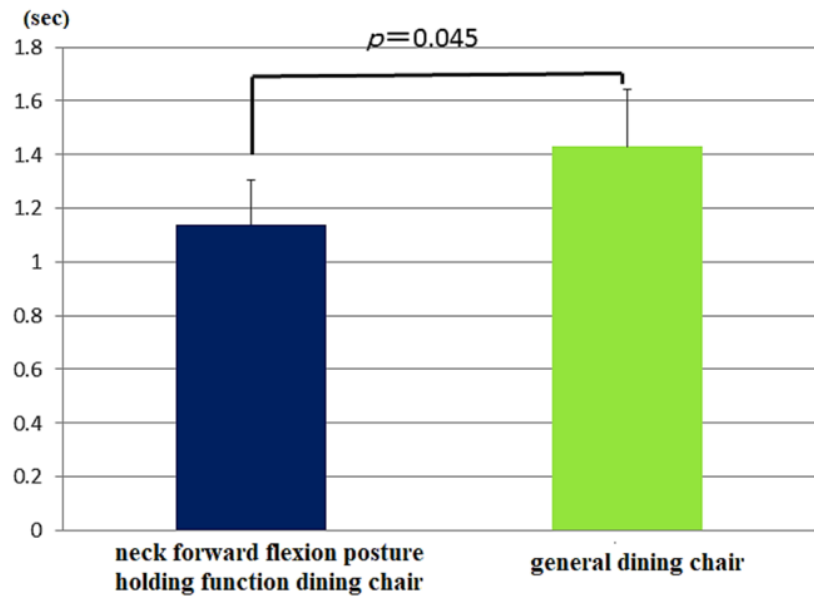

Fig-4

\begin{tabular}{|c|c|c|c|c|c|c|}
\hline \multicolumn{7}{|c|}{ (Table-1) Measurement results of the subject $(2017 / 12 / 22)$} \\
\hline & & & & & $\begin{array}{c}\text { Suprahyoid muscle } \\
\text { group activity } \\
\text { time(sec) (average } \\
\text { of } 3 \text { measurements) }\end{array}$ & $\begin{array}{l}\text { Suprahyoid muscle group } \\
\text { activity time (sec) (average } \\
\text { of } 3 \text { measurements) }\end{array}$ \\
\hline S.No & Sex & Age & $\begin{array}{l}\text { Height } \\
\text { (cm) }\end{array}$ & $\begin{array}{c}\text { Body Weight } \\
\text { (KG) }\end{array}$ & $\begin{array}{c}\text { NFF Posture } \\
\text { Holding Function } \\
\text { Chair }\end{array}$ & General Dining Chair \\
\hline 1 & $\mathrm{~F}$ & 73 & 148 & 45 & 1.13 & 2.1 \\
\hline 2 & $\mathrm{~F}$ & 71 & 153 & 52 & 0.33 & 0.56 \\
\hline 3 & $\mathrm{~F}$ & 65 & 160 & 63 & 0.5 & 0.7 \\
\hline 4 & M & 73 & 168 & 53 & 0.38 & 1.31 \\
\hline 5 & M & 81 & 164 & 68 & 0.9 & 0.75 \\
\hline 6 & M & 77 & 167 & 60 & 1.125 & 0.5 \\
\hline 7 & M & 72 & 165 & 52 & 0.71 & 0.78 \\
\hline 8 & M & 81 & 156 & 65 & 1.45 & 1.6 \\
\hline 9 & M & 80 & 160 & 45 & 1.83 & 2.03 \\
\hline 10 & M & 67 & 168 & 63 & 1.45 & 1.81 \\
\hline 11 & M & 69 & 169 & 71 & 2.13 & 2.38 \\
\hline 12 & M & 65 & 181 & 59 & 1.98 & 2.71 \\
\hline 13 & M & 65 & 165 & 65 & 0.91 & 1.05 \\
\hline \multicolumn{2}{|c|}{ Average } & 72.23 & $163 \cdot 38$ & 58.53 & 1.14 & 1.43 \\
\hline
\end{tabular}


middle-aged and elderly people with declining trunk and lower extremity muscles, upright pelvic sitting posture for eating falls into an unstable situation. It is considered that the activity duration of the suprahyoid muscles is extended because it was difficult to maintain a desirable upright pelvic eating the NFF posture in a general dining chair. For the case of a new system dining chair that allows stable holding of the desired NFF feeding posture by supporting the upright pelvis at both the ischial tuberosity and both PSIS sections. It is thought that the chair that stably holds the NFF eating posture can realize shortening of the activity duration of the suprahyoid muscles by not requiring excessive iliopsoas muscles activity. The NFF posture holding function dining chair was significantly shorter than the general dining chair in the suprahyoid muscles activity time [7].

Though eight subjects were unable to measure and analyze due to the thick subcutaneous fat at the measurement point, the swallowing test by the muscle measurement may the most objective verification method that was not influenced by the individual subjectivity of the tester and the subject. Based on the electromyographic measurement results, the NFF posture was a posture that enables ideal smooth swallowing [8]. Also, from an ergonomic viewpoint, the NFF postural holding of the fixed support system in the pelvic area reduces postural collapse (forward slide suppression of both ischial tuberosity) in the eating movement and facilitates phlegm expulsion for crisis avoidance with the freely upper body movement [9]. A new type of the NFF posture holding dining chair of self-support function with high attitude retention ability and high crisis avoidance ability is expected to provide safe and smooth swallowing meals to elderly people, especially the solitary elderly and older couples who do not have families or caregivers.

We will expect future verification about the remarkable difference between the suprahyoid muscles action potential duration and the posture holding ability depending on the time history of the posture holding function dining chair and the general dining chair. Since this experiment was subjected to healthy subjects, it is necessary to further verify whether those with cerebrovascular disorder, dysphagia, and dementia will lead to similar results.

\section{Conclusion}

By 2050, one in six people in the world's population will be 65 years old. At present Germany, Italy, France, Sweden China, Singapore, and Thailand are moving towards an aging society and China will become an aging country with an unprecedented world's largest elderly population before becoming rich (economically developed countries).

China is struggling and focusing on measures to extend its healthy life expectancy, and measures to reduce the elderly requiring long-term care reported by Chinese newspaper (People's Daily and Global Times).

We hope this valuable scientific information will be shared with the world's newspapers and media as the "Breaking News" to all the elderly people in the world whose swallowing function is declining. Especially, to China (People's Daily and Global Times), which is struggling to cope with the largest number of elderly people in the world.

\section{Acknowledgement}

A dining chair with the function of holding the neck forward flexion posture by the ideal posture holding method realized by acquiring new findings. The university headquarters that understands the great potential and the social contribution of the dining chair to support and protect the diet of the elderly people whose swallowing function continues to decline. I would like to thank the researchers who carried out the most objective evaluation results and the university headquarters that paid $90 \%$ of the verification fee.

\section{Conflict of interests}

None

\section{References}

[1] Ministry of Health, Labor and Welfare: Overview of population statistics for 2011, annual report 
Citation: Fukaura J, Tetsushi T, Kaneko H, et al., "Verification of the functional effect of upright pelvis fixed support system dining chair with independence support function corresponding to eating and drinking trouble of the elderly". Asp Biomed Clin Case Rep, vol.2, no.2: 9-14, 2019.

(round numbers).

[2] Siebens AA, "Rehabilitation For Swallowing Impairment”. In: Kottke FJ, Lehmann IF (eds.): Krusen's Handbook of Physical Medicine and Rehabilitation, 4th ed. Philadelphia, WB Saunders: 765-77, 1990.

[3] Kuramoto N, Jayatilake D, Hidaka K, et al., "Smartphone-based swallowing monitoring and feedback device for mealtime assistance in nursing homes”. 2016 38th Annual International Conference of the IEEE Engineering in Medicine and Biology Society (EMBC), Orlando, FL: 5781-84, 2016.

[4] Naruse T, Ando T, Bando N, and a study on the comfort evaluation and functional design of wooden chairs by the engineering method of the Horibe (vi) on the angle of back seat suitable for work chairs, Gifu Institute of Living Technology: 2004

[5] Inui R, Morikiyo K, Nakajima T, et al., "Muscle activity in swallowing muscles and cervical muscles during swallowing of neck angle change Influence on, Japan". The Journal of Dysphagia Rehabilitation, vol.16, no.3: 269-75, 2012.

[6] OKITSU T, ARITA M, SONODA S, et al., "The Surface Electromyography on Suprahyoid Muscles during Swallowing”. Jpn J Rehabil Med, vol.35, no.4: 241-44, 1998.

[7] Sakuma T, Kida I, "Relationship between ease of swallowing and deglutition-related muscle activity in various postures". J Oral Rehabil, vol.37, no.8: 583-89, 2010.

[8] Woo HS, Park SH, Jung MY, et al., "The effects of cranio-cervical flexion on activation of swallowingrelated muscles". J Oral Rehabil, vol.39, no.11: 805-11, 2012.

[9] Schultheiss C, Wolter S, Schauer T, et al., "Effect of body position on coordination of breathing and swallowing”. HNO, vol.63, no.6: 439-46, 2015. 